\title{
Late emotional effects of rehabilitation during childhood and their impact on coping with deafness in adulthood
}

Journal of Health Psychology 2020, Vol. 25(4) 522-537

(C) The Author(s) 2017

Article reuse guidelines: sagepub.com/journals-permissions DOI: $10.1177 / 1359105317719581$ journals.sagepub.com/home/hpq ๑SAGE

\section{Adva Eichengreen and Dan Hoofien}

\begin{abstract}
This study examined potential influences of childhood rehabilitation and over-normalization on coping with disability in adulthood. A total of 88 deaf and hard-of-hearing students were interviewed retrospectively about their childhood and completed self-report questionnaires assessing psychological environment-directedness and present emotional and behavioral coping with deafness. It was partially supported that over-normative parental attitude negatively affected coping with deafness through the mediation of elevated environmentdirectedness. Intensity of childhood rehabilitation was not found to affect adulthood coping with deafness. However, post-hoc analyses supported this mediation path when rehabilitation had been intensive yet not prolonged. Alleviating changes in the perception and practice of rehabilitation are suggested.
\end{abstract}

\section{Keywords}

deaf, disability acceptance, false-self, hard-of-hearing, normalization, psychodynamic theory, rehabilitation

\section{Introduction}

Rehabilitation practices are aimed at reducing activity limitations experienced by people with disabilities (World Health Organization (WHO), 2002). Historically, rehabilitation is rooted in the medical model, which views disability as "a feature of the person" that "calls for medical or other treatment or intervention, to 'correct' the problem with the individual” (WHO, 2002: 8). Based on normalizing liberalist and individualist conceptions (Davis, 2006a; Stiker, 1999 [1997]), modern rehabilitation has been aimed at correcting bodily or mental differences for the sake of integrating people with disabilities within the larger society. However, equality of rights for persons with disabilities has been based under this approach on the transparent standard of the non-disabled body, appearance, and function (Stiker, 1999 [1997]). Alongside its invaluable contributions to the well-being of people with disabilities, rehabilitation, both as a professional field and as a socio-cultural worldview, has been criticized for locating the "problem" within persons with impairments rather than in the social structures that disable them (Charlton, 1998; Oliver, 1990). Alternative

The Hebrew University of Jerusalem, Israel

\section{Corresponding author:}

Adva Eichengreen, Department of Psychology, The Hebrew University of Jerusalem, Mount Scopus, Jerusalem 919050I, Israel.

Email: adva.eichengreen@gmail.com 
social and cultural perspectives have been suggested, part of whom were adopted within the International Classification of Functioning, Disability and Health (ICF) biopsychosocial definition of disability (WHO, 2002) and are increasingly adopted by rehabilitation scholars and stakeholders (Gibson, 2009).

\section{Psycho-emotional effects of rehabilitation and normalization of children with disabilities}

Comparing to the extensive study of rehabilitation and normalization from sociological, historical, and philosophical perspectives, little was it examined from critical psychosocial points of view, especially in the context of children with disabilities. Stiker (1999 [1997]) pointed at the "double constraint" that weighs on rehabilitated people, who on the one hand may internalize an essential sense of impaired and deviant identity and on the other hand are expected to behave "as if nothing were wrong" (p. 152). The social pressure to pass as nondisabled may come at emotional costs of selfhatred or self-denial (French, 1993; Linton, 1998; Samuels, 2003). Such emotional effects can be considered as a form of psycho-emotional disablism, a concept which refers to psychological restrictions on the well-being of people with disabilities, such as shame or low self-esteem, which are created by social and relational barriers (Reeve, 2004; Simpson and Thomas, 2015; Thomas, 1999). Few studies, however, have directly addressed the subjective experiences of children with disabilities (Watson, 2012). Applying qualitative analyses, Connors and Stalker (2007) found that children with physical, sensory, or learning disabilities tended to emphasize in their self-presentation their similarity to non-disabled peers. Many of these children lived in educational and familial environments that did not encourage talking about the disability. The researchers suggested that they lacked a positive language to think and talk about disability-related experiences (Connors and Stalker, 2007). Environments which neglect or deny self-experiences that relate to disability are not uncommon, especially when the disability is partial or non-visible, such as with children who are partially sighted (French, 1993) or hard-of-hearing (Meadow-Orlans et al., 2003). More specific to rehabilitation efforts, directing one's energy to a continued self-correction may at times overburden children and their families (Gibson et al., 2009). Intensive rehabilitation, such as physical or speech therapy, under certain circumstances, may impair other aspects important for one's quality of life, such as autonomy in decision-making and self-determination, positive self-perception, satisfactory social relations (Giangreco, 1996; Oliver, 1990), or in the case of children with disabilities "time to just be kids" (Gibson, 2012). Several studies conducted with children with physical disabilities, such as cerebral palsy (see review at Gibson et al., 2009), found that subjective well-being or life satisfaction did not correspond directly to functioning level. These studies question traditional assumptions of pediatric rehabilitation and highlight more generally the need to further study the implications of rehabilitation for children, with special focus on the viewpoint of the children themselves (Gibson et al., 2009).

\section{The relations between intensive rehabilitation and normalization and elevated environment-directedness - the case of deaf and hard-of-hearing children}

In a previous study (Eichengreen et al., 2016) on which this study is based, we hypothesized certain psychodynamic long-term effects of rehabilitation and integration processes on 88 deaf and hard-of-hearing $(\mathrm{d} / \mathrm{hh})$ young adults. ${ }^{1}$ These hypothesized effects were based on the psychoanalytic concept of the False Self defense. This concept is widely used in the psychoanalytic literature to describe a mental defense of alienation from inner self-experiences, as well as an elevated sensitivity and compliance with environmental expectations and demands (Winnicott, 1965a [1960]). The concept emerged as part of a developmental theory on the child's emerging 
sense of self. According to Winnicott's theory, the infant's sense of self, or mental existence, develops in a complete dependency on the adaptation of the parental environment to the infant's needs. In case of accumulated failures in parental adaptations, an existential anxiety arises in the child, to which he/she responds by adjusting to the caregiver's needs and expectations, at the expense of being aware and express his/her own psychological states (Winnicott, 1965a [1960]). From infancy onward, environmental adaptations are crucial for the formation of a firm, alive, and authentic sense of self in lessening degrees and are still important well into adolescence (e.g. Khan, 1974; Winnicott, 2005a [1971]). As a universal defense mechanism, the False Self is described in the clinical literature as ranging on a continuum from healthy to pathological, where in its rigid state the person complies compulsively with internalized expectations of other people or may feel inner emptiness, detachment, and inauthenticity (Khan, 1974; Winnicott, 1965a [1960], $1965 b$ [1960]). When tested empirically, various False Self measures were found to correlate significantly with negative affects, depressive symptoms, anxiety, loneliness, and low self-esteem (Eichengreen and Hoofien, 2017; Harter, 1997; Weir and Jose, 2010).

The False Self is usually described in the clinical literature as resulting from particular aspects of parent-child relationship. However, such process may also be relevant to children with disabilities who need to adapt themselves to environmental expectations in the process of "overcoming" the disability. We found that an intensive rehabilitating and normalizing environment in childhood may generate what we termed as compliant falseself, or high environment-directedness, in adulthood. High environment-directedness implies an emotional dependency on other people's validation as a preliminary condition to self-acceptance and self-expression, preoccupation with the way one is perceived by others, and a tendency to comply with expectations and demands of other people in order to quiet inner fear or insecurity (Eichengreen et al., 2016). Two risk factors were found in that study to be positively associated with high environment-directedness at adulthood. The first was intensive rehabilitation in childhood, which included speech and hearing training that started at a young age, lasted for several years, and involved frequent work of the child with both professionals and with parents at home. The second variable was parental "over-normative" attitude. These were parents whose wish to see their child as completely "normal" was accompanied by lack of awareness or empathic acknowledgement of deafness-related needs or difficulties experienced by the child. For example, parents who could not understand why the child had social difficulties (related to the hearing loss) and thought he/she should manage "just like everyone else." The results of that study demonstrated how intensive auditory and speech therapy or parental demand of the child to adapt himself/herself to hearing norms and standards, alongside their advantages, may at the same time weaken the child's sense of self and impair the ability in adulthood for independent self-approval and self-soothing. The possible influence of the cultural context was also supported in that study at an intergroup level, as the $\mathrm{d} / \mathrm{hh}$ group presented higher environmentdirectedness when compared to hearing students who were matched to them according to sociodemographic variables such as gender, age, educational level, and socio-economic background (Eichengreen et al., 2016). In this study we further explore the potential effects of this psychodynamic process on the ability to positively accept and cope with deafness.

\section{The effect of rehabilitation and normalization processes on coping with hearing loss}

Acknowledgement and acceptance of disability-related needs is fundamental for successful psychosocial adaptation (Livneh, 2001). Integrating the disability in one's self-concept predicts better satisfaction with life (Bogart, 2014). In the case of $\mathrm{d} / \mathrm{hh}$ people, positive acceptance of the hearing loss, making individual adaptations, and asserting one's need of environmental adaptations may be crucial for successful interpersonal communication. These are therefore vital for social, familial, 
educational, and vocational participation (Erdman, 2006). However, sometimes in contrast to rehabilitation of adults, children's rehabilitation, such as physiotherapy or speech therapy, is more attenuated toward functional normalization than to the child's psychological experience (Giangreco, 1996). When the child is integrated in regular social and educational settings, especially in the case of the non-visible hearing loss, many parents as well as the children themselves prefer to think they "got over" the disability (Harvey, 2003). In the case of $\mathrm{d} / \mathrm{hh}$ children, in spite of significant medical and technological advances including cochlear implantations, children still face some degree of hearing difficulties, especially in circumstances of background noise or group discussions (Bat-Chava and Deignan, 2001; Wheeler et al., 2007). Their educational mainstreaming does not guarantee psychological adjustment to hearing loss and hence better socio-emotional well-being. For example, in a qualitative study conducted with seven $\mathrm{d} / \mathrm{hh}$ adolescents, the interviewees recalled feeling ashamed of the hearing difficulties and refraining from sharing them with hearing peers (Israelite et al., 2002). Experiences such as hiding one's hearing aids or even avoid using them were reported by mainstreamed $\mathrm{d} /$ $\mathrm{hh}$ adolescents in other qualitative studies as well (Kent and Smith, 2006; Punch and Hyde, 2005). Accepting the deafness is particularly challenging for these children in light of the social difficulties that many $\mathrm{d} / \mathrm{hh}$ children experience due to communication barriers and stigma (Israelite et al., 2002; Most, 2007; Punch and Hyde, 2005; Zaidman-Zait and Dotan, 2017). Having been separated from the company of other $\mathrm{d} / \mathrm{hh}$ peers, they may feel lonely and isolated, especially in group interactions during adolescence. This may negatively affect their social self-concept and even limit their career decision-making. Using selfreport questionnaires with 68 deaf adolescents, Van Gent et al. (2012) found that, comparing to norms of hearing peers at the same educational level, deaf adolescents who were mainstreamed in regular schools felt they had lower social acceptance and social competence. In interviews conducted with 12 mainstreamed $\mathrm{d} / \mathrm{hh}$ adolescents, Punch and Hyde (2005) found that low social self-esteem was leading their participants to doubt their ability to succeed in the job market and even limited their choices in the process of career decision-making. Such processes may deeply influence their well-being in adulthood. Fellinger et al. (2007) compared various aspects of quality of life and mental health between 373 hard-of-hearing adults, 232 signing-deaf, and norms of the hearing population adjusted by age and gender. It was found that hard-of-hearing people reported on higher levels of mental distress comparing to hearing people and were more socially isolated comparing to both the hearing and the signingDeaf communities $^{2}$ (Fellinger et al., 2007).

\section{Introducing environment-directedness as a mediating factor between rehabilitation in childhood and coping with deafness in adulthood}

In an attempt to contribute to the understanding of the complex impact of rehabilitation of $\mathrm{d} / \mathrm{hh}$ on their coping with deafness, a psychodynamic perspective is suggested. We suggest that one's attitude toward disability-related parts of the self cannot be separated from one's experience of the self in general. Whenever excessive adaptation to environmental demands and expectations takes place in the rehabilitation process, subsequent elevated mental directedness to the environment would impact the ability to accept and reveal disability-related needs. People who are more dependent on external validation in order to gain self-approval may prefer to pass as hearing in order not to jeopardize their social acceptance. A potential dissonance or conflict between their own and others' experiences may provoke an anxiety to which they react by adaptation to ablebodied norms/behaviors, instead of demanding adaptations to their own needs. We therefore hypothesize that rehabilitation and normalization 
processes may negatively impact one's attitude toward disability through the mediation of elevated environment-directedness. Testing this on the $\mathrm{d} / \mathrm{hh}$ sample described in Eichengreen et al. (2016), we suggest an indirect mediation path between childhood risk factors for environmentdirectedness - intensive rehabilitation program and over-normative parental attitude - and difficulty in adulthood in accepting and revealing the hearing loss in interpersonal communications.

In particular, we hypothesize that intensive auditory and speech services during childhood, conducted with both professionals and parents (parents are often instructed to do auditory and speech exercises with the child at home on a daily basis and to correct the child's speech during daily conversations), may create a demanding environmental atmosphere which encourages in the child an elevated self-adaptation to the environment, such as elevated sensitivity to other people's judgment, expectations, or approval. This in turn may hinder the ability (tested in adulthood) to positively accept parts of the self that do not correspond to "hearing" norms. This is reflected by the degree of emotional acceptance of the hearing loss (e.g. feeling open and not ashamed about it), as well as the behavioral ability to manage the deafness adaptively in conversations instead of, for instance, hiding it by pretending to understand. The same mediation path was hypothesized for parental over-normative attitude as an independent variable. Parents who tend to ignore aspects of the child's coping with hearing loss, out of their wish to see the child as completely "normal," may transmit to the child a message that he/she should adapt themselves to other people's expectations before attending to their own needs and feelings. Figure 1 summarizes the hypothesized mediation model of the study.

\section{Method}

\section{Participants}

Participants were $88 \mathrm{~d} / \mathrm{hh}$ students from various Israeli higher education institutes. Table 1 displays their background characteristics. All

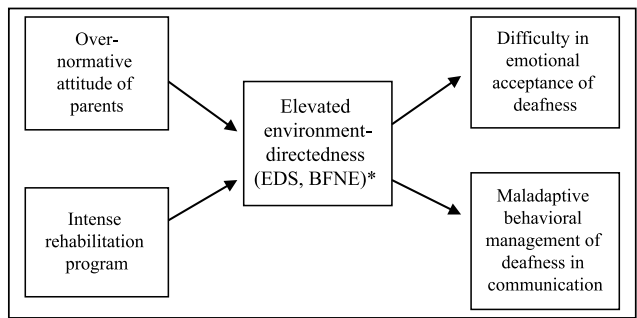

Figure I. Summary of the mediation model hypothesized between childhood risk factors and adulthood coping with deafness.

*Environment-directedness was assessed by two measures: Environment-Directedness Scale and Brief Fear of Negative Evaluation Scale. Each mediation path was computed for each of these measures separately, summing up in eight mediation paths in total.

Table I. Background characteristics of the participants $(n=88)$.

\begin{tabular}{lrrc}
\hline & $M$ & SD & Range \\
\hline Age & 24.13 & 2.50 & $18-30$ \\
Education (years) & 14.63 & 1.70 & $12-20$ \\
Siblings & 2.59 & 1.72 & $0-10$ \\
Parents' educational status $^{\mathrm{a}}$ & 3.51 & 1.29 & $1-6$ \\
Socio-economic status $^{\mathrm{b}}$ & 4.49 & .79 & $2-7$ \\
\hline & $n$ & $\%$ \\
\end{tabular}

Gender

$\begin{array}{lll}\text { Female } & 50 & 56.8 \\ \text { Male } & 38 & 43.2\end{array}$

Religious

$\begin{array}{lll}\text { No } & 72 & 81.8\end{array}$

$\begin{array}{lll}\text { Yes } & 16 & 18.2\end{array}$

Involved in prolonged relationship

No $\quad 46 \quad 52.3$

$\begin{array}{lll}\text { Yes } & 42 & 47.7\end{array}$

Parents living together

$\begin{array}{lll}\text { No } & 18 & 20.5 \\ \text { Yes } & 70 & 79.5\end{array}$

SD: standard deviation.

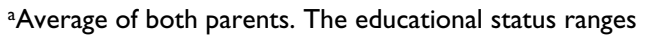
from I (less then I2years) to 6 (third degree or beyond). ${ }^{b}$ Average of childhood and present. The socio-economic scale ranges from I (very low) to 7 (very high).

the participants had hearing loss since birth or the first 3 years of life. All of them were individually integrated in hearing classes 
throughout their school years, where they were the only $\mathrm{d} / \mathrm{hh}$ child in the class. Among them, 85 percent used spoken language only, whereas the rest knew sign language but still used spoken language as their main mode of communication. The degrees of hearing loss varied from mild hearing loss or unilateral deafness $(22 \%)$ to moderate or moderately severe $(28 \%)$ or severe to profound hearing loss $(50 \%)$. Eight participants $(9 \%)$ had additional disabilities (ear/face deformation, limp, ADD (Attention Deficit Disorder) or anosmia). Eight of the participants were born in former USSR countries, two were born in the United States, and one was born in Lebanon. They all immigrated to Israel during their childhood. A total of 23 participants $(26 \%)$ had siblings or parents with hearing loss.

\section{Procedure}

Invitations to participate in the study were sent to suitable participants via the National Insurance Institute of Israel (NIII). In collaboration with the research and rehabilitation departments of NIII, invitation letters were sent to all $\mathrm{d} / \mathrm{hh}$ students who received services from the NIII. The invitation letters were provided with contact details of one of the researchers and at no stage were the researchers exposed to the recipients' names or addresses. The research was also advertised by organizations for and of people with hearing loss, classified advertisements, hearing institutes, and universities' websites and accessibility coordinators. Students who voluntarily made a contact with the researcher were asked about information required for the participation criteria. An interviewer subsequently made a private appointment with each suitable participant. The interviewees read and signed an informed consent form, filled a packet of questionnaires, and afterward were interviewed for about 1 hour. At the end of the meeting, each participant received a payment equivalent to $25 \mathrm{US} \$$. The research was approved by the ethics committee of the Hebrew University.

\section{Measures}

\section{Childhood risk factors}

Intensity of the auditory-verbal rehabilitation program. The intensity of rehabilitation during childhood was assessed by seven open questions to which the respondents were asked to give written answers. The questions focused on factual data about childhood speech and hearing training (e.g. "Who did the training with you?" "Were family members involved?" "How often did you practice?"). The answers were coded according to four categories: the age when the rehabilitation started (scoring ranged from 1 to 3 , with younger age receiving higher score), the duration of the training in years (scoring ranged from 1 to 4 , longer duration was given higher score), the extent to which parents were involved in addition to professionals (scoring ranged from 1 to 4 , with a higher score given when family members were involved in addition to professionals), and the weekly frequency of the exercises (scored 1 if frequency was less than two times a week, scored 2 if frequency was two times a week or more). The total sum of scores ranged between 4 and 13. A score of zero was given in case if the respondent had not participated in any significant auditory and speech program. A score of 13 points signified the highest level of intensity of the rehabilitation program.

Parental over-normative attitude. The extent to which the parents viewed their child as normative, according to the respondents' retrospective reports, was measured during an in-depth interview on the following scales: (1) Parental perceptions of the deafness as significantly disabling, that is, low expectations of the child due to deafness. For example, a participant who felt that his parents did not expect him to succeed in school and to acquire a good profession in life because of his deafness, in contrary to their expectations of his hearing brother. (2) Parental perceptions of the deafness as slightly disabling/limiting. (3) Parents who thought that their child is able to succeed like any hearing child and at the same time, acknowledged the 
child's needs related to deafness. (4) Overnormative attitude-parents who denied the deafness or its related needs or had difficulties in empathic understanding of its related experiences. Examples for over-normative attitude ranged from parents who refrained from fitting the child hearing aids (in cases of mild hearing loss) to "old immigrants" parents who chose on a regular basis to speak their native language at the dinner table although they could speak Hebrew, despite the fact that the child couldn't participate in the familial conversations due to having difficulty in hearing languages other than Hebrew; or parents who were not understanding or emphatic to the child's social difficulties at school. The measure of parental over-normative attitude was assessed during an in-depth interview about personal, social, and familial aspects of coping with deafness. The protocols of the interviews' questions and categories of analysis were devised in a preliminary pilot study (Eichengreen, 2014) that was carried out with 12 interviewees who were not part of this study's sample. All the interviews in this study were transcribed and quantitatively analyzed by the first author and two more trained judges. All the judges expertized in the fields of clinical and rehabilitational psychology or special education and were well acknowledged with the deaf and hard-of-hearing population. The first author and one more judge coded all the interviews $(N=88)$. The third judge coded the cases in which there was a disagreement $(N=39)$. The judges were blind to each other's coding in order to allow for an independent process. In cases of disagreement, the score chosen by the majority of the judges (two out of three) was selected. If there was a disagreement between all three judges, the most moderate coding was selected. Interrater reliability was computed with intraclass correlation coefficient (ICC). ICC for two judges $(N=88)$ was .544 $(p=.000 ; 95 \%$ confidence interval $(\mathrm{CI})=.378$, $.676)$. For three judges, $(N=39)$ ICC was .428 $(p=.000 ; 95 \% \mathrm{CI}=.233, .616)$, which is defined as fair (Cicchetti, 1994). Since more than half of the participants shared the same score of 3 (parents who saw their child as "normal" and at the same time acknowledged and attended his/her deafness), this variable was recoded as a dummy variable according to the median score: 0 (none over-normative; formerly scores 1-3) and 1 (over-normative; formerly scores 3.5-4).

\section{Environment-directedness measures}

Environment-Directedness Scale. This 14-item inventory assesses sensitivity to the way other people mirror or judge one's feelings ("Sometimes I take hints from those around me in order to know what I am supposed to think and feel"), need of other people's acceptance and approval in order to express feelings and thoughts ("I sometimes suppress my feelings when I'm afraid that others will not approve of them"), and tendency to comply with other people's expectations ("Sometimes I feel that I automatically adapt myself to what other people expect of me") (Eichengreen and Hoofien, 2017). The respondents are asked to rank each item on a 5-point Likert scale. A high score indicates high environment-directedness.

The Environment-Directedness Scale (EDS) was devised on the basis of previously published questionnaires assessing awareness to the self from the other's perspective, externalized self-perception, or aspects of the False Self (Jack, 1991; Sheldon, 1996; Sherry, 1998) .An initial pool of 23 items was sent for content judgment to three experienced senior clinical psychologists, following which all items were retained. The scale was subsequently passed to a sample of 226 university students for psychometric assessment. Following reliability and item analyses, a final version of 14 items was devised and passed again to a sample of 208 students. The final version displays high internal reliability: Cronbach's alpha is .91 (Eichengreen and Hoofien, 2017). Pearson's correlations indicate that high environmentdirectedness is significantly related to other self- and environment-directedness measures at the expected directions - self-determination $(-.46)$, self-relatedness (-.55), and fear of negative evaluation (.80). It was also found to relate to measures of well-being: negative affects (.41), loneliness (.38), satisfaction with life 
$(-.25)$, and positive affects $(-36)$ (Eichengreen and Hoofien, 2017).

Brief Fear of Negative Evaluation Scale. This 8-item 5-point Likert scale version of the Brief Fear of Negative Evaluation Scale (BFNE) was utilized in this study as a second measure of environment-directedness (Leary, 1983). The fear to be negatively evaluated by others, measured by this scale ("I am frequently afraid of other people noticing my shortcomings"), is an aspect of the emotional dependency on others' approval which characterizes environmentdirectedness. The BFNE is a widely used questionnaire and was found to relate inter-alia to measures of social anxiety, self-judgment, and depression (Leary, 1983; Weeks at al., 2008).

The scale was translated into Hebrew in a procedure of translation and back-translation and later on passed to two distinct samples of more than 200 university students each for psychometric evaluation (for further details see Eichengreen, 2014). Cronbach's alpha of the Hebrew version is very high, .94, and similar to the reliability of the original scale, .95 (Weeks et al., 2008). Pearson's correlations indicate that BFNE relates to other self- and environmentdirectedness measures at the expected directions: self-relatedness (-.46), self-determination $(-.45)$, and environment-directedness (.80). The scale also correlates with measures of wellbeing: negative affects (.43), loneliness (.51), satisfaction with life $(-.35)$, and positive affects (-.38) (Eichengreen, 2014).

Measures of emotional and behavioral attitudes toward the hearing loss. The following scales were taken from the Communication Profile for the Hearing Impaired (CPHI; Demorest and Erdman, 1987). The CPHI is a well-established rehabilitation measure that consists of 25 scales. It estimates a wide variety of factors affecting the communication quality of people with hearing loss for the purpose of improving the rehabilitation process (Demorest and Erdman, 1987). The scales have been utilized extensively in clinical and in research settings (Erdman, 2006). They have been used interna- tionally and have been translated into several languages (Mokkink et al., 2009). The following scales were translated into Hebrew in a procedure of translation and back-translation and later on passed to a sample of $219 \mathrm{~d} / \mathrm{hh}$ respondents for psychometric evaluation and validation (Eichengreen, 2014).

Emotional Acceptance Scale. This 9-item 5-point Likert scale assesses difficulties in admitting or revealing the hearing loss as well as negative feelings that individuals direct toward themselves in relation to hearing/communication difficulties ("I find it difficult to tell others that I have a hearing problem," "I feel stupid when I have to ask someone to repeat what they've said"). The scale is inverted so that a high score indicates positive emotional acceptance. The scale combines items taken from Self Acceptance and Acceptance of Loss scales from the CPHI, two scales that are highly correlated (Erdman, 2006). The scales predict adherence to the rehabilitation program and positive treatment outcome (Erdman, 2006). Cronbach's $\alpha$ of the Emotional Acceptance Hebrew version is high, .85 (Eichengreen, 2014), and similar to the reliability range of the original scales in various studies, .84-.90 (Mokkink et al., 2009).

Maladaptive Behaviors Scale. This 8-item 5-point Likert scale assesses behaviors that interfere with effective communication, such as avoidance, pretending to understand, dominating conversations, or ignoring others ("I avoid conversing with others because of my hearing loss," "When I don't understand what someone has said, I pretend that I understood it"). The scoring of the responses is inverted so that a high score means fewer maladaptive behaviors or more positive coping. The Hebrew version is identical to the original one except for the exclusion of one item which was found previously as loading low on this scale and was recommended for removal (Mokkink et al., 2009). Cronbach's $\alpha$ of the Hebrew version is good, .76 (Eichengreen, 2014) and similar to the reliability range of the original scale in various studies, .76-.81 (Mokkink et al., 2009). 
Table 2. Scale reliability (Cronbach's $\alpha$ ), descriptive statistics, and scale intercorrelations. ${ }^{a}$

\begin{tabular}{|c|c|c|c|c|c|c|c|}
\hline Variable & $\alpha$ & M & SD & I & 2 & 3 & 4 \\
\hline I. EDS & .92 & 2.63 & .81 & - & .66 & -.54 & -.39 \\
\hline 2. BFNE & .93 & 2.73 & 1.03 & .66 & - & -.46 & -.52 \\
\hline 3. Behaviors & .81 & 3.90 & .68 & -.54 & -.46 & - & .60 \\
\hline 4. Emotional & .88 & 3.57 & .89 & -.39 & -.52 & .60 & - \\
\hline
\end{tabular}

SD: standard deviation; EDS: Environment-Directedness Scale; BFNE: Brief Fear of Negative Evaluation Scale. Behaviors: Maladaptive Behaviors Scale (high score $=$ no maladaptive behaviors); Emotional: Emotional Acceptance Scale (high score $=$ acceptance).

aAccording to the scales' distributions, Pearson's $r$ is calculated for intercorrelations between EDS and BFNE and Spearman's $r$ is calculated for all the rest. All correlations are significant at $p$ (two-tailed) $<.00 \mathrm{I}$.

\section{Statistical analyses}

Mediation paths were tested using a bootsrapping method, which generates an empirical representation of the sampling distribution of the indirect effect, yielding a CI for the mediation path coefficient. Bootsrapping is recommended due to it being robust to violations of the normality assumption (Hayes, 2009). We used $k=10,000$ bootstrap samples for 95 percent CIs. In order to strengthen the validity assessment of the results, each mediation analysis was replicated separately for two measures of environment-directedness and for two measures of the attitude toward the disability.

\section{Results}

\section{Descriptives}

Scales' reliabilities, descriptive statistics, and intercorrelations are displayed in Table 2. All scales presented good to very high internal reliability (Cronbach's $\alpha=.81-.93$ ). The correlation between EDS and Brief Fear of Negative Evaluation (BFNE) scale was high $(r=.66)$, which supports their comprehension as measuring a common construct-environment-directedness/compliant false-self. The correlation between the Maladaptive Behaviors scale and the Emotional Acceptance scale was high as well $(r=.60)$, indicating that they belong to a common variable assessing similar aspects of coping with disability (maladaptive behaviors correlating with low emotional acceptance). The intercorrelations between measures of environment-directedness and coping with disability were all significant, ranging from medium to large ( $r=-.39$ to -.54 ). These findings support our assumption about the associations between one's attitude toward disability-related parts of the self and one's attitude toward the self in general. Furthermore, the findings support the hypothesized negative correlation between emotional and behavioral acceptance of disability and environment-directedness.

\section{Mediation analyses}

The results concerning over-normative parental attitude, summarized in Table 3, were partially confirmed. EDS was found to significantly mediate, in the expected directions, between over-normative attitude of parents and negative emotional attitude toward the disability, as well as maladaptive behavioral coping. The indirect effect was full or partial, respectively. The indirect mediation paths with BFNE failed to reach a significant level.

The hypothesis regarding intensive rehabilitation was not supported since none of the mediation paths were significant. In an attempt to further understand these findings, we conducted post-hoc analyses based on splitting the participants according to the median score of the intensity of rehabilitation. The findings of the explorative analyses are described at the following section.

\section{Post-hoc analyses}

In order to expand our understanding of the rejection of the hypothesis regarding the intensity of rehabilitation, we conducted several tests which suggested a possible non-monotone relation between intensity of rehabilitation and environment-directedness. When divided according to the median score of the intensity of rehabilitation, most of the samples $(n=64)$ displayed positive spearman correlations between intensity of 
Table 3. Mediation coefficients: over-normative attitude of parents as an independent variable.

\begin{tabular}{|c|c|c|c|c|}
\hline \multirow{2}{*}{$\begin{array}{l}\text { Environment- } \\
\text { directedness } \\
\text { measures (mediating } \\
\text { variables) }\end{array}$} & \multirow{2}{*}{$\begin{array}{l}\text { Coping with } \\
\text { hearing loss } \\
\text { (dependent } \\
\text { variables) }\end{array}$} & \multicolumn{3}{|c|}{ Mediation coefficients } \\
\hline & & Total & Direct & Indirect \\
\hline \multirow[t]{2}{*}{ EDS } & Behaviors & $-.432(p=.006)$ & $-.264(p=.046)$ & $-.168\left(95 \% \mathrm{Cl}^{\mathrm{a}},-.390\right.$ to $\left.-.0 \mathrm{II}\right)$ \\
\hline & Emotional & $-.501(p=.014)$ & $-.324(p=.084)$ & $-.177(95 \% \mathrm{Cl},-.427$ to $-.0 \mathrm{I} 3)$ \\
\hline \multirow[t]{2}{*}{ BFNE } & Behaviors & $-.432(p=.006)$ & $-.318(p=.022)$ & $-.113(95 \% \mathrm{Cl},-.297$ to .020$)$ \\
\hline & Emotional & $-.501(.014)$ & $-.325(p=.059)$ & $-.176(95 \% \mathrm{Cl},-.432$ to .036$)$ \\
\hline
\end{tabular}

EDS: Environment-Directedness Scale; Cl: confidence interval; BFNE = Brief Fear of Negative Evaluation Scale.

Behaviors: Maladaptive Behaviors Scale; Emotional: Emotional Acceptance Scale $(N=88)$.

Bold values represent significant results.

aBias corrected bootstrap confidence intervals $(k=10,000)$.

rehabilitation and EDS $(r=.29, p<.05)$ or BFNE $(r=.32, p<.01)$. In contrast, the group at the highest level $(n=24$, mean score of intensity of rehabilitation $=11.3$, standard deviation $(\mathrm{SD})=.9$ comparing to $M=4, \mathrm{SD}=3.5$ for the rest of the sample) displayed a non-significant correlation $(r=-.13$ for BFNE) or even a significant negative one ( $r=-.43, p<.05$ for EDS) thus "turning over" the positive direction of the association between intensity of rehabilitation and environment-directedness measures. The parameter of intensity of rehabilitation score is computed as a combination of four sub-components: starting age, frequency, the extent of parental involvement, and duration of the program in years (see measures section for further details). MannWhitney $U$ tests demonstrated that it is the last component which distinguished the highest level group. When compared to other participants who have participated in rehabilitation programs, the highest level group was distinguished not by the intensity of the rehabilitation program during childhood but by its duration well beyond the early years (mean duration of years was 10.9 for this group, $\mathrm{SD}=4.8$, range $=4-20$; comparing to $M=1.7, \mathrm{SD}=2.1$, range $=0-10$ years for the rest of the participants). Duration of rehabilitation was also found to correlate significantly with severity of the hearing loss $(r=.60, p<.001)$, low auditory function $(r=.47, p<.001)$, low speech intelligibility $(r=.41, p<.01)$, and usage of sign language in addition to speech $(r=.46, p<.001)$. It is possible that students who had participated in especially prolonged rehabilitation due to relatively deviant auditory and verbal functioning may had been more resistant as a group to normalization processes and their potential emotional effects. Whereas this explanation needs further research, we analyzed the hypothesized mediation paths separately for the two subgroups in order to allow for meaningful data. The findings of the post-hoc mediation analyses are presented in Table 4. For the highest level group $(n=24)$, only one mediation path was significant: a full positive indirect effect of intensity of rehabilitation on behavioral coping through the mediation of environment-directedness. For the rest of the sample $(n=64)$, all four mediation paths showed significant full negative indirect effects. Both EDS and BFNE significantly mediated between the intensity of rehabilitation during childhood and negative emotional, as well as behavioral, levels of coping with deafness in adulthood.

\section{Discussion}

The relations that were found in this study between environment-directedness measures and emotional and behavioral coping with deafness exemplify the importance of viewing the processes of coping with disability within a wider psychodynamic context. Participants who displayed greater environment-directedness had more difficulty in admitting the hearing loss and revealing it in interpersonal communication. 
Table 4. Post-hoc mediation coefficients: intensive rehabilitation as an independent variable.

\begin{tabular}{|c|c|c|c|c|c|}
\hline \multirow{2}{*}{$\begin{array}{l}\text { Duration of } \\
\text { rehabilitation } \\
\text { in years }\end{array}$} & \multirow{2}{*}{$\begin{array}{l}\text { Environment- } \\
\text { directedness } \\
\text { measures } \\
\text { (mediating } \\
\text { variables) }\end{array}$} & \multirow{2}{*}{$\begin{array}{l}\text { Coping } \\
\text { with } \\
\text { hearing loss } \\
\text { (dependent } \\
\text { variables) }\end{array}$} & \multicolumn{3}{|c|}{ Mediation coefficients } \\
\hline & & & Total & Direct & Indirect \\
\hline \multirow{4}{*}{$\begin{array}{l}\text { Short to } \\
\text { moderate } \\
\text { duration }^{\mathrm{a}} \\
(N=64)\end{array}$} & EDS & Behaviors & -.07 I $(p=.006)$ & $-.034(p=.121)$ & $-.037\left(95 \% \mathrm{Cl}^{\mathrm{b}},-.077\right.$ to -.007$)$ \\
\hline & & Emotional & $-.030(p=.360)$ & $.013(p=.674)$ & $-.043(95 \% \mathrm{Cl},-.096$ to -.008$)$ \\
\hline & BFNE & Behaviors & -.07 I $(p=.006)$ & $-.045(p=.064)$ & $-.026(95 \% \mathrm{Cl},-.062$ to -.006$)$ \\
\hline & & Emotional & $-.030(p=.360)$ & $.011(p=.702)$ & $-.04 \mathrm{I}(95 \% \mathrm{Cl},-.086$ to $-.0 \mathrm{II})$ \\
\hline \multirow{4}{*}{$\begin{array}{l}\text { Long } \\
\text { duration }^{\mathrm{a}} \\
(\mathrm{N}=24)\end{array}$} & EDS & Behaviors & $-.008(p=.945)$ & $-.109(p=.357)$ & $.101(95 \% \mathrm{Cl}, .003$ to .348$)$ \\
\hline & & Emotional & $.280(p=.117)$ & $.212(p=.279)$ & $.068(95 \% \mathrm{Cl},-.033$ to .346$)$ \\
\hline & BFNE & Behaviors & $-.008(p=.945)$ & $-.016(p=.87 I)$ & $.008(95 \% \mathrm{Cl},-.166$ to .157$)$ \\
\hline & & Emotional & $.280(p=.117)$ & $.262(p=.037)$ & $.018(95 \% \mathrm{Cl},-.006$ to .166$)$ \\
\hline
\end{tabular}

EDS: Environment-Directedness Scale; CI: confidence interval; BFNE: Brief Fear of Negative Evaluation Scale.

Behaviors: Maladaptive Behaviors Scale; Emotional: Emotional Acceptance Scale.

Bold values represent significant results.

aShort to moderate: $M=1.7, S D=2.1$, range $=0-10$; Long: $M=10.9, S D=4.8$, range $=4-20$.

bBias corrected bootstrap confidence intervals $(k=10,000)$.

Their negative feeling toward the hearing loss had an external effect on their capability for full and authentic participation in social interactions. From a psychodynamic perspective, it is possible that their elevated sensitivity to social expectations made it more difficult for them to accept and reveal disability needs which may not be easily understood or approved by other people.

Interestingly, this process of weakening of the self was found to relate to over-normative attitudes of parents, a variable which was partially found to have a negative effect on emotional and behavioral coping with deafness through the mediation of the environmentdirectedness measure. Similar mediation paths were also found, in post-hoc explorations, with respect to intensive auditory and speech training during childhood, up to certain duration in years as will be discussed later. Clearly, both parents and professionals perceive normalization and rehabilitation as means for improving the child's ability for independent and confident coping with disability. However, such practices are often based on the medical model of disability (Oliver, 1990), which locates the "problem" within the child. The child needs, according to this model, to correct parts of him/herself and invest elevated efforts in self-adaptations in order to look and function as non-disabled as possible. Such efforts may restrict the conditions which, according to psychodynamic theory, are necessary for developing strong, livable, and authentic sense of self. Among them are opportunities for the child to be in an "unintegrated" relaxation in the presence of the caregiver (Winnicott, 1979 [1965]), a state in which the infant or the child has no active purpose or interest nor does he have to respond to external impingements, which enables him to feel spontaneous sensations as an integral part of himself, environment which enables the child to internally and gradually integrate mental experiences with psychosomatic ones (Winnicott, 1978 [1949]), and environmental adaptations which enable the child to develop age-appropriate sense of creative omnipotence, necessary for free play and healthy psychological development (Winnicott, 1965a [1960], 2005b [1971]). Parents who are involved in didactic rehabilitational practices, as well as parents who intensely seek for normalization of the child, are at risk of neglecting these aspects in the child's development. From a psychodynamic perspective, lack of mirroring and validation of the child's experiences and needs may leave him/her more dependent on other people's 
perceptions in order to gain self-approval (Miller, 2000 [1979]). This may be relevant whenever intensive normalization is accompanied by a lack of awareness and validation of the child's difficulties and needs that are related to the disability or even to the rehabilitation process itself.

The research hypothesis according to which intensive rehabilitation will negatively affect coping with deafness through the mediation of environment-directedness was not supported. However, post-hoc analyses suggest that it failed due to a non-monotone relation that existed between intensity of rehabilitation and environment-directedness. Our findings regarding the differentiation between the participants according to the duration of the rehabilitation program suggest that the positive relation between intensity of rehabilitation and environment-directedness characterized participants who displayed relatively improved auditory and verbal functioning. These participants, who comprised the majority of the sample, showed significant mediation paths in the hypothesized directions, that is, intensive rehabilitation negatively affected their emotional and behavioral coping with deafness through the mediation of environment-directedness measures. The rehabilitation these participants have undergone may have been intensive during childhood (starting at a young age, frequent training, training involving parents at home in addition to professionals) but did not last long beyond the early years. These findings suggest that children who are more likely to benefit from auditory-verbal training and whose post-rehabilitation functioning is closer to "normal" standards, thus making the disability less visible or severe, may be more likely to internalize the normalization process and its subsequent potential emotional outcomes. Another possible factor that may explain why participants who were involved in prolonged rehabilitation did not present negative mediating relations between rehabilitation and coping with deafness has to do with method of provision of rehabilitation services in Israel. Many d/hh children receive auditory and speech services in a public organization (non-governmental organization (NGO)) for $\mathrm{d} /$ hh children which facilitates other activities such as social meetings with other $\mathrm{d} / \mathrm{hh}$ children. When a child continues with auditory and speech therapy well into late childhood and adolescence, it may also provide him/her with opportunities to socialize with other $\mathrm{d} / \mathrm{hh}$ children, which may encourage positive attitude toward deafness and lessen the need to attenuate to hearing norms. A previous study (Fellinger et al., 2008) identified $\mathrm{d} / \mathrm{hh}$ children with severe hearing loss as a risk group for externalized mental health problems when compared to children with moderate, as well as profound, hearing loss. The higher risk of emotional difficulties in this group was explained by their relatively marginalized position, that is, being neither fully part of the hearing nor of the signing-deaf worlds. This may be relevant to the participants of this study as well, who underwent intensive rehabilitation due to the severity of their hearing loss but were not part of the Deaf community.

\section{Implications}

Taking the psychodynamic perspective into consideration, we suggest that children may benefit from participating in self-focused interventions or experiences in a way that is inherent to the rehabilitation process. By this, we mean any practice which would encourage the child's ability to attend and express sensations, feelings, and needs, especially when these are not naturally shared by his/her non-disabled environment. For instance, providing children with opportunities to talk and reflect upon the way they experience the auditory and speech exercises or how they feel in everyday communications at home and in school; teaching children techniques (e.g. meditation, mindfulness, or techniques taken from cognitive-behavioral therapy) for self-recognition and regulation of physical and mental tension. These can be integrated within the auditory and speech sessions, as well as in focus groups with other $\mathrm{d} / \mathrm{hh}$ children, which can normalize and validate the child's experiences. Mentalizing the children's experiences can also be assisted by integrating psychologists or art-therapists as part of the 
rehabilitation team and program. Most importantly, parents should be involved as key factors in assisting the child in developing self-approval capabilities. As part of this process, children would also benefit from learning how to manage disability-related experiences and how to incorporate them into their self-concept and interpersonal interactions, including the development of self-advocacy skills (Olkin, 2007).

A philosophical glance would ask how we can entail rehabilitative practices without the implicit encouragement of the child to internalize the medical model of disability, that is, the view of disability as an individual flaw that should be corrected. Is there a way to sieve the practical advantages of rehabilitation from its potential costs for the child's sense of self, which may generate a form of psycho-emotional disablism (Simpson and Thomas, 2015)? This question can be referred to by the conceptual distinction, made by Bourdieu (1990 [1980]), between practical and pragmatic faith. Practical faith is compared by Bourdieu (1990 [1980]) to the acquisition of mother tongue, in which "the child learns at the same time to speak the language (which is only ever presented in action, in his own or other people's speech) and to think in (rather than with) the language" (p. 67). The language and culture we are born to mold our ways of thought and internal identity by the unconscious practice of their usage. We are living them unreflectively - they are our "immanence in the world" (Bourdieu, 1990 [1980]: 66). A pragmatic faith, however, is equated by Bourdieu to a foreign language which is learned consciously. A person adopts the rules of the game for pragmatic reasons, knowing that they are arbitrary, contrary to primary learning. Could rehabilitation of children, which sometimes starts at a very young age and always through actions, be introduced to them as a pragmatic faith? Some steps may promote such a pragmatic view. Rehabilitation can be treated conceptually as just one arena of the child's life, of which the child can rest. The child may be introduced to alternative views of disability, deeply shared by his/her family and friends. Examples can range from affirmative or cultural model (e.g. Bogart, 2014; Swain and
French, 2000; Olkin, 2007) which views disability as a positive part of one's identity or culture and stresses proud affiliation with the disability community (i.e. Deaf culture), to universalist perception of disability as a normal encompassing experience shared by every human being (e.g. Davis, 2006b).

\section{Limitations and suggestions for future research}

The conclusions that can be drawn from the study should be tempered by the partial support provided for its hypotheses. The negative influence of the rehabilitation on coping with deafness was supported only in post-hoc analyses. As such, the differences between participants according to the length of the rehabilitation program they had undergone and their corresponding level of functioning should be further studied in larger samples. Investigations with populations who have not been fully "normalized," such as sign language users, could improve our understanding of the variables that may moderate the relation between rehabilitation and normalization processes and the extent of their internalization by the child. In addition, due to the retrospective nature of the study the mediation analyses cannot prove by themselves causal effects. The interpretation of causality is based on time differences reported by the participants (childhood risk factors comparing to present personal state) and the a priori theoretical background for the hypotheses. Yet, it cannot be rejected that interviewees' present personality state may have affected their interpretation of the past. We tried to partially respond to this limitation by employing relative factual criteria in defining past risk factors, such as explicit behavior of parents or obtaining factual data about the rehabilitation program. Another limitation, which is inherent to psychological investigations, is that children's personality attributes may had influenced their subsequent interpretation and interactions with the environment (e.g. a child with initial high environment-directedness for different reasons would tend less to share his feelings with his 
parents thus reinforcing over-normative attitude of parents). Future research would benefit from employing longitudinal designs, addressing directly children's subjective experiences, and estimating the influence of alternative views of disability, as well as interventions for strengthening the child's sense of self.

\section{Acknowledgements}

The authors wish to express their gratitude to the students who participated in the study and to thank Daphna Dobrenko, Shlomit Warshavsky, and Tamar Spanier for their thorough and sensitive work in conducting the research. They would also like to thank Dr Reuma Gadassi for her helpful suggestions and for the reviewers of this manuscript for their most helpful comments and suggestions.

\section{Declaration of conflicting interests}

The author(s) declared no potential conflicts of interest with respect to the research, authorship, and/or publication of this article.

\section{Funding}

The author(s) disclosed receipt of the following financial support for the research, authorship, and/or publication of this article: The research was supported by the Harry and Sylvia Hoffman Leadership and Responsibility Program of the Hebrew University, Israel Foundation Trustees, Israel National Insurance Institute, Eric and Fuga Neuberger Foundation, Salinski Foundation, the Sigmund Freud Center for Study and Research in Psychoanalysis at the Hebrew University, and Israel Association of University Women.

\section{Notes}

1. The term rehabilitation is used in this study to refer to auditory and speech training conducted from a young age with professionals, and sometimes with parents at home, in order to advance the child's usage of spoken communication.

2. The upper case D is used by Deaf people to denote a cultural identity and a sense of belonging to the Deaf community, with its own unique language, art, history, and inner codes. This is contrasted to the lower case $\mathrm{d}$, which denotes the traditional medical definition and conception of deafness.

\section{References}

Bat-Chava Y and Deignan E (2001) Peer relationships of children with cochlear implants. Journal of Deaf Studies and Deaf Education 6: 186-199.

Bogart KR (2014) The role of disability self-concept in adaptation to congenital or acquired disability. Rehabilitation Psychology 59: 107-115.

Bourdieu P (1990 [1980]) Belief and the body. In: Bourdieu P (ed.) The Logic of Practice (trans. R Nice). Palo Alto, CA: Stanford University Press, pp. 66-79.

Charlton JI (1998) Nothing about Us without Us: Disability, Oppression and Empowerment. Berkeley, CA: University of California Press.

Cicchetti DV (1994) Guidelines, criteria, and rules of thumb for evaluating normed and standardized assessment instruments in psychology. Psychological Assessment 6(4): 284-290.

Connors C and Stalker K (2007) Children's experiences of disability: Pointers to a social model of childhood disability. Disability \& Society 22: 19-33.

Davis LJ (2006a) Constructing normalcy: The bell curve, the novel, and the invention of the disabled body in the nineteenth century. In: Davis LJ (ed.) The Disability Studies Reader (2nd edn). New York: Routledge, pp. 3-16.

Davis LJ (2006b) The end of identity politics and the beginning of dismodernism: On disability as an unstable category. In: Davis LJ (ed.) The Disability Studies Reader (2nd edn). New York: Routledge, pp. 231-242.

Demorest ME and Erdman SA (1987) Development of the communication profile for the hearing impaired. Journal of Speech and Hearing Disorders 52: 129-143.

Eichengreen A (2014) Potential risk factors for elevated false self defense in rehabilitation and integration processes: Self-directedness and environment-directedness among hard-of-hearing young adults who are integrated in the hearing society. Doctoral Dissertation, The Hebrew University of Jerusalem, Jerusalem, Israel. Available at: arad.mscc.huji.ac.il/dissertations/W/ JMS/001903588_1.pdf

Eichengreen A and Hoofien D (2017) Psychometric analyses of new measures of false-self defense: Self-Relatedness and Environment-Directedness Scales. European Journal of Psychological Assessment 33: 75-143. 
Eichengreen A, Hoofien D and Bachar E (2016) Empirically based suggested insights into the concept of false-self defense: Contributions from a study on normalization of children with disabilities. Journal of the American Psychoanalytic Association 64: 107-132.

Erdman SA (2006) Clinical interpretation of the CPHI. Perspectives on Aural Rehabilitation and Its Instrumentation 13: 3-18.

Fellinger J, Holzinger D, Gerich J, et al. (2007) Mental distress and quality of life in the hard of hearing. Acta Psychiatrica Scandinavica 115: 243-245.

Fellinger J, Holzinger D, Sattel H, et al. (2008) Mental health and quality of life in deaf pupils. European Child \& Adolescent Psychiatry 17: 414-423.

French S (1993) "Can you see the rainbow?" The roots of denial. In: Swain J, Finkelstein V, French S, et al. (eds) Disabling BarriersEnabling Environments. London: SAGE, pp. 69-77.

Giangreco MF (1996) "The stairs didn't go anywhere!" A self-advocates reflections on specialized services and their impact on people with disabilities. Physical Disabilities: Education and Related Service 14: 1-12.

Gibson BE (2012) The politics of walking. Nordic Network on Disability Research. Available at: http://nndr.org/ (accessed 1 December 2012).

Gibson BE, Darrah J, Cameron D, et al. (2009) Revisiting therapy assumptions in children's rehabilitation: Clinical and research implications. Disability and Rehabilitation 31: 14461453.

Harter S (1997) The personal self in social context: Barriers to authenticity. In: Ashmore RD and Jussim L (eds) Self and Identity, Fundamental Issues, vol. 1. New York: Oxford University Press, pp. 81-105.

Harvey MA (2003) Psychotherapy with Deaf and Hard-of-Hearing Persons: A Systemic Model (2nd edn). Mahwah, NJ: Lawrence Erlbaum.

Hayes AF (2009) Beyond Baron and Kenny: Statistical mediation analysis in the new millennium. Communication Monographs 76: 408420 .

Israelite N, Ower J and Goldstein G (2002) Hardof-hearing adolescents and identity construction: Influences of school experiences, peers, and teachers. Journal of Deaf Studies and Deaf Education 7: 134-148.
Jack DC (1991) The silencing the self scale. Unpublished manuscript.

Kent B and Smith S (2006) They only see it when the sun shines in my ears: Exploring perceptions of adolescent hearing aid users. Journal of Deaf Studies and Deaf Education 11: 461-476.

Khan MM (1974) The Privacy of the Self. New York: International Universities Press.

Leary MR (1983) A brief version of the Fear of Negative Evaluation Scale. Personality and Social Psychology Bulletin 9: 371-375.

Linton S (1998) Claiming Disability: Knowledge and Identity. New York: New York University Press.

Livneh H (2001) Psychosocial adaptation to chronic illness and disability: A conceptual framework. Rehabilitation Counseling Bulletin 44: 151160.

Meadow-Orlans KP, Mertens DM and Sass-Lehrer MA (2003) Hard of hearing children: Forgotten and overlooked. In: Olson SK (ed.) Parents and Their Deaf Children: The Early Years. Washington, DC: Gallaudet University Press, pp. 39-57.

Miller A (2000 [1979]) The Drama of the Gifted Child (trans. Y Goldberg). Tel Aviv, Israel: Dvir Press.

Mokkink LB, Knol DL, Zekveld AA, et al. (2009) Factor structure and reliability of the Dutch version of seven scales of the Communication Profile for the Hearing Impaired (CPHI). Journal of Speech, Language and Hearing Research 52: 454-464.

Most $T$ (2007) Speech intelligibility, loneliness, and sense of coherence among deaf and hardof-hearing children in individual inclusion and group inclusion. Journal of Deaf Studies and Deaf Education 12: 495-503.

Oliver M (1990) The Politics of Disablement: A Sociological Approach. New York: St. Martin's Press.

Olkin R (2007) Disability-affirmative therapy and case formulation: A template for understanding disability in a clinical context. Counseling and Human Development 39: 1-20.

Punch R and Hyde M (2005) The social participation and career decision-making of hard-of-hearing adolescents in regular classes. Deafness \& Education International 7: 122-138.

Reeve D (2004) Psycho-emotional dimensions of disability and the social model. In: Barnes $\mathrm{C}$ and Mercer G (eds) Implementing the Social Model 
of Disability: Theory and Research. Leeds: The Disability Press, pp. 83-100.

Samuels E (2003) My body, my closet: Invisible disability and the limits of coming-out discourse. GLQ: A Journal of Lesbian and Gay Studies 9: 233-255.

Sheldon KM (1996) The Social Awareness Inventory: Development and applications. Personality and Social Psychology Bulletin 22: 620-634.

Sherry M (1998) The false self: Its conceptualization and assessment. Doctoral Dissertation, Bar-Ilan University, Ramat Gan, Israel.

Simpson J and Thomas C (2015) Clinical psychology and disability studies: Bridging the disciplinary divide on mental health and disability. Disability and Rehabilitation 37: 1299-1304.

Stiker HJ (1999 [1997]) The birth of rehabilitation. In: Stiker HJ (ed.) A History of Disability (trans. W Sayers). Ann Arbor, MI: The University of Michigan Press, pp. 121-190.

Swain J and French S (2000) Towards an affirmation model of disability. Disability \& Society 15: $569-582$.

Thomas C (1999) Female Forms: Experiencing and Understanding Disability. Buckingham: Open University Press.

Van Gent T, Goedhart AW, Knoors HE, et al. (2012) Self-concept and ego development in deaf adolescents: A comparative study. Journal of Deaf Studies and Deaf Education 17: 333-351.

Watson N (2012) Theorizing the lives of disabled children: How can disability theory help? Children \& Society 26: 192-202.

Weeks JW, Heimberg RG and Rodebaugh TL (2008) The Fear of Positive Evaluation Scale: Assessing a proposed cognitive component of social anxiety. Journal of Anxiety Disorders 22: 44-55.

Weir KF and Jose PE (2010) The perception of false self scale for adolescents: Reliability, validity, and longitudinal relationships with depressive and anxious symptoms. British Journal of Developmental Psychology 28: 393-411.
Wheeler A, Archbold S, Gregory S, et al. (2007) Cochlear implants: The young people's perspective. Journal of Deaf Studies and Deaf Education 12: 303-316.

Winnicott DW (1965a [1960]) Ego distortion in terms of true and false self. In: Khan MR (ed.) The Maturational Processes and the Facilitating Environment. London: Hogarth Press and the Institute of Psychoanalysis, pp. 140-152.

Winnicott DW (1965b [1960]) The theory of the parent-infant relationship. In: Khan MR (ed.) The Maturational Processes and the Facilitating Environment. London: Hogarth Press and the Institute of Psychoanalysis, pp. 37-55.

Winnicott DW (1978 [1949]) Mind and its relation to the psyche-soma. In: Khan MR (ed.) Collected Papers: Through Paediatrics to Psycho-Analysis. London: Hogarth Press and the Institute of Psychoanalysis, pp. 243-354.

Winnicott DW (1979 [1965]) The capacity to be alone. In: Khan MR (ed.) The Maturational Processes and the Facilitating Environment. London: Hogarth Press and the Institute of Psychoanalysis, pp. 29-36.

Winnicott DW (2005a [1971]) Contemporary concepts of adolescent development and their implications for higher education. In: Rodman FR (ed.) Playing and Reality. London: Routledge, pp. 186-203.

Winnicott DW (2005b [1971]) Playing: A theoretical statement. In: Rodman FR (ed.) Playing and Reality. London: Routledge, pp. 51-70.

World Heath Organization (WHO) (2002) Towards a Common Language for Functioning, Disability and Health ICF. Geneva: WHO. Available at: http://www.who.int/classifications/icf/training/ icfbeginnersguide.pdf

Zaidman-Zait A and Dotan A (2017) Everyday stressors in deaf and hard of hearing adolescents: The role of coping and pragmatics. Journal of Deaf Studies and Deaf Education 22: 257-268. 